BMC

Evolutionary Biology

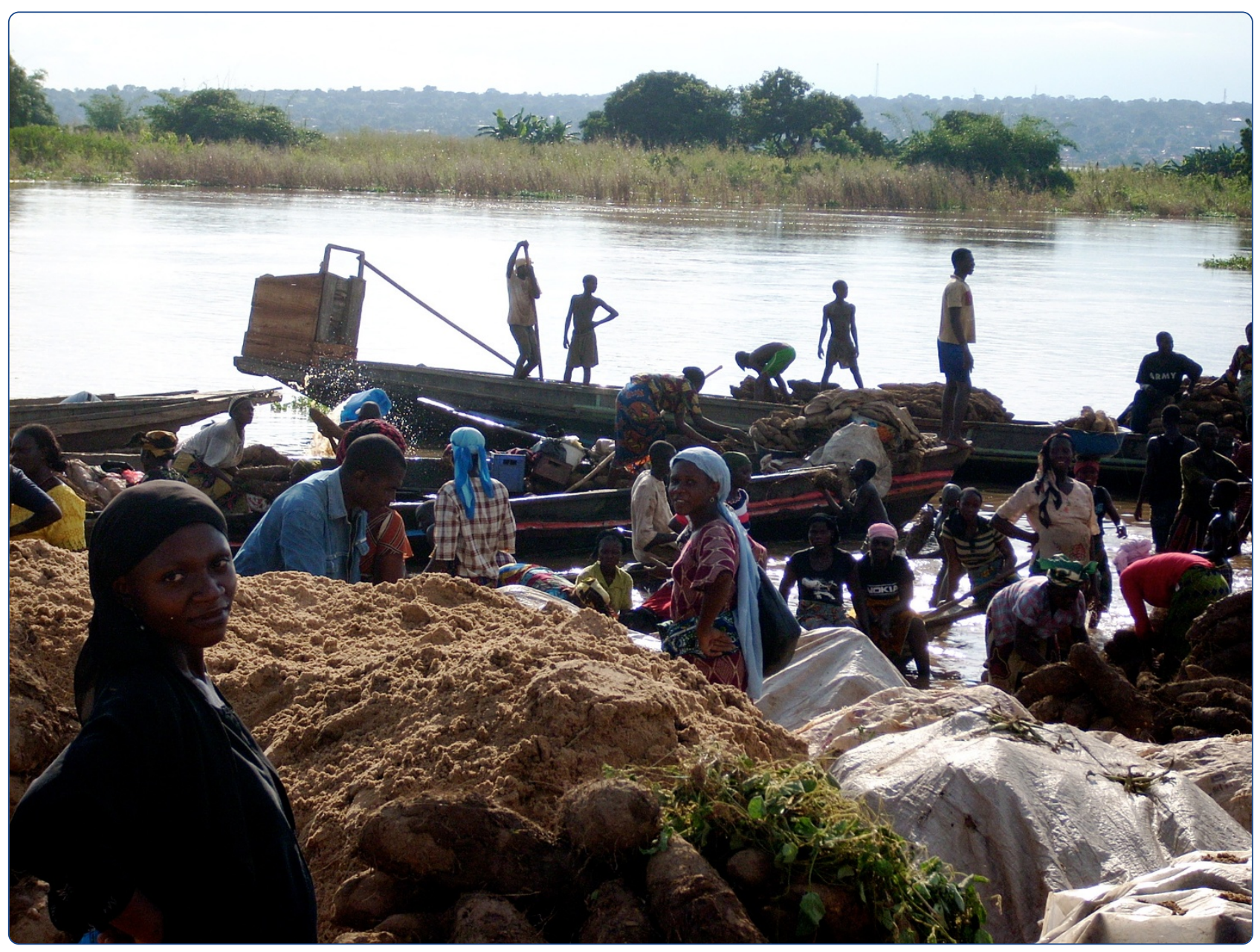

The influence of habitats on female mobility in Central and Western Africa inferred from human mitochondrial variation

Montano et al. 


\title{
The influence of habitats on female mobility in Central and Western Africa inferred from human mitochondrial variation
}

\author{
Valeria Montano ${ }^{1,7^{*}+}$, Veronica Marcari ${ }^{1 \dagger}$, Mariano Pavanello ${ }^{2,3,5}$, Okorie Anyaele ${ }^{4}$, David Comas ${ }^{5}$,
} Giovanni Destro-Bisol ${ }^{1,3,5}$ and Chiara Batini $6^{*}$

\begin{abstract}
Background: When studying the genetic structure of human populations, the role of cultural factors may be difficult to ascertain due to a lack of formal models. Linguistic diversity is a typical example of such a situation. Patrilocality, on the other hand, can be integrated into a biological framework, allowing the formulation of explicit working hypotheses. The present study is based on the assumption that patrilocal traditions make the hypervariable region I of the mtDNA a valuable tool for the exploration of migratory dynamics, offering the opportunity to explore the relationships between genetic and linguistic diversity. We studied 85 Niger-Congo-speaking patrilocal populations that cover regions from Senegal to Central African Republic. A total of 4175 individuals were included in the study.

Results: By combining a multivariate analysis aimed at investigating the population genetic structure, with a Bayesian approach used to test models and extent of migration, we were able to detect a stepping-stone migration model as the best descriptor of gene flow across the region, with the main discontinuities corresponding to forested areas.

Conclusions: Our analyses highlight an aspect of the influence of habitat variation on human genetic diversity that has yet to be understood. Rather than depending simply on geographic linear distances, patterns of female genetic variation vary substantially between savannah and rainforest environments. Our findings may be explained by the effects of recent gene flow constrained by environmental factors, which superimposes on a background shaped by pre-agricultural peopling.
\end{abstract}

Keywords: Mitochondrial DNA, Migration, Population genetic structure, Bayesian inference, Western Central Africa

\section{Background}

Understanding how human populations interact and admix is one of the primary aims of human evolutionary genetics. To date, three main factors have been studied in detail which could be possible determinants of gene flow within and among human groups: geography, language and social structure.

\footnotetext{
* Correspondence: Valeria.Montano@vetmeduni.ac.at; cb334@le.ac.uk ${ }^{\dagger}$ Equal contributors

'Dipartimento di Biologia Ambientale, Sapienza Università di Roma, P.le Aldo Moro 5, 00185, Rome, Italy

${ }^{6}$ Department of Genetics, University of Leicester, Leicester LE1 7RH, UK

Full list of author information is available at the end of the article
}

Geographical factors have been shown to play an important role in shaping genetic structure, at both inter and intra-continental levels (e.g. [1-7]). Along with the evidence which indicates a geographical continental structure of human populations that is systematically revealed by the analysis of nuclear loci [2-5], natural barriers have also been indicated as one of the possible elements driving the distribution of human diversity at a local level [6,7].

The relationship between linguistic and genetic diversity has been investigated in numerous studies aimed at understanding how cultural factors may shape gene pools (e.g. [8-10]). Their results highlight a variable degree of correlation, depending not only on the geographic location and

\section{Ciomed Central}


scale adopted, but also on the genetic loci analysed when the same set of populations is considered [7,11-13].

Finally, following the seminal study by Seielstad et al. [14], there has been a surge of interest in the role of sexbiased matrimonial mobility, an important aspect of human social structure. In accordance with the prevalence of patrilocal habits, where women move to their husbands households after the marriage, higher female transgenerational migration rates have been inferred at both local and continental level in most populations studied [14-18].

Even though the vast literature accumulated over twenty years (e.g. $[8,9])$ has produced important insights into the structure of human genetic variation, there are two critical points in the current approaches which need to be adequately considered when planning new research work. Inferences based on extent and patterns of gene flow are usually indirect, being derived from analyses of genetic distances among populations, and assuming simplified migration schemes. This is, in fact, the case of the island model $[14,18]$. Additionally, the relation between genetic variation and geography has been generally investigated simply by focusing on physical linear distances among populations [3,13,19-21], an approach which might be misleading if we consider how human mobility can be influenced by geographical and environmental barriers or even facilitated by natural corridors on both local and global scales [7,22,23].

In this context, given their high cultural and linguistic diversity and their complex history, African populations probably represent one of the most interesting case studies. Recent studies on large-scale datasets regarding autosomal markers (both STRs and SNPs) support the role of both geography and language in explaining the distribution of genetic variation in Africa [24,25]. Among the four linguistic groups found in the continent, the Niger-Congo includes populations with the widest geographical distribution, spanning from the west to the east and south, and yet the highest common autosomal genetic ancestry (see $[24,25]$, but also $[2,4])$. This is particularly surprising when considering the complexity of this phylum and its history, for the most part deduced from linguistic data. Due to the uncertain position of Kordofanian languages in the NC tree, the initial centre of diffusion of the phylum is still matter of debate. Ehret (2000) proposed the Nuba Mountains in Sudan, whereas Blench (2006) suggested the Western regions of Africa. On the other hand, the later history of this phylum is generally agreed upon. In summary, around 10-8 thousand years ago (kya), NC languages moved through the savannah of Western Africa, reaching the rainforest $2 \mathrm{ky}$ later. Subsequently, the Bantu languages expanded (5 kya) from Cameroon into the equatorial forest of the Congo, and southward. Finally, they spread to the east (the region of great lakes) and to the south of the rainforest (Angola) around 3kya and from there to the south [26]. However, genetic data indicate that the expansion of Bantu speaking individuals through the African continent could have been more complex than previously thought [27-29] and as also previously pointed out by language and archaeology $[30,31]$.

In this work, we investigated the genetic structure and the patterns of gene flow in a broad dataset ( 85 populations, 5 typed ex novo and 80 collected from the literature) of individuals settled in an area spanning from Central to Western Africa. The populations under study inhabit both the savannah and the rainforest regions, and all speak languages belonging to the Niger-Congo phylum [32] and share traditional patrilocal behaviour, which is here assumed to have been constant through time [33-36]. Therefore, the migration of male individuals should be culturally more limited than females and the analysis of maternal lineages, rather than malespecific and autosomal loci, should allow for the exploration of patterns related to geographical habitat differences and/or linguistic barriers. It is in fact reasonable to expect that female gene flow is the main contributor to gene exchange between populations. In a patrilocal context, if either linguistics or geography is playing a role in structuring genetic variation among the populations under study, this should have left a signature in the distribution of mtDNA variation. On the other hand, when the distribution of male lineages is found to be correlated with linguistic diversity $[12,13,21]$, it is difficult to determine whether such a correlation is a cause or effect of genetic isolation, due to the lack of formal models relating linguistic to genetic evolution. Last but not least, the hypervariable region I of mitochondrial DNA (mtDNA) is at present the only source of information on human genetic variation which provides an adequate genetic coverage of populations settled in the region under study $[1,37]$. We first explore the distribution of maternal lineages using a multivariate statistical method (the discriminant analysis of principal components, DAPC; [38]). Thereafter, we compare the fit of three different migration models as descriptors of the relationships among the clusters previously identified, using a Bayesian approach [39-41]. By combining these two methods, our study suggests that the genetic structure of Central and Western African populations may be explained by the effects of recent gene flow constrained by environmental factors, which superimposes on a background shaped by pre-agricultural peopling.

\section{Results}

Intra-population variation and genetic distances

Intra-population diversity parameters are shown in Table 1. HD ranges between 0.932 in Eviya and 1.000 in 
Table 1 Intra-population summary statistics

\begin{tabular}{|c|c|c|c|c|c|c|c|c|}
\hline Population & Abbreviation & $\mathbf{N}$ & $\mathrm{K}$ & $S$ & HD & MNDP & Fs & $\mathrm{Fs}(\mathrm{p})$ \\
\hline \multicolumn{9}{|l|}{ CENTRAL } \\
\hline Bakaka & Bak & 50 & 36 & 59 & $0.983+/-0.008$ & $9.821+/-4.571$ & -17.339 & 0.000 \\
\hline Bamileke & Bam & 48 & 36 & 55 & $0.988+/-0.007$ & $8.108+/-3.821$ & -22.157 & 0.000 \\
\hline BatekeN & Ban & 53 & 43 & 59 & $0.988+/-0.008$ & $8.782+/-4.116$ & -24.77 & 0.000 \\
\hline Bassa & Bas & 47 & 40 & 61 & $0.993+/-0.006$ & $9.433+/-4.408$ & -24.685 & 0.000 \\
\hline BatekeS & Bat & 50 & 23 & 42 & $0.944+/-0.017$ & $6.621+/-3.179$ & -5.416 & 0.062 \\
\hline Benga & Ben & 50 & 26 & 55 & $0.952+/-0.015$ & $9.922+/-4.616$ & -4.526 & 0.094 \\
\hline Beti & Bet & 48 & 29 & 52 & $0.968+/-0.012$ & $8.758+/-4.112$ & -9.449 & 0.006 \\
\hline Foumban & Caf & 107 & 71 & 67 & $0.989+/-0.003$ & $7.959+/-3.728$ & -24.73 & 0.000 \\
\hline Wum & Caw & 115 & 63 & 57 & $0.983+/-0.004$ & $7.519+/-3.537$ & -24.782 & 0.000 \\
\hline Bankim & Cbt & 34 & 24 & 44 & $0.968+/-0.017$ & $7.686+/-3.673$ & -9.603 & 0.001 \\
\hline Duma & Dum & 47 & 29 & 55 & $0.973+/-0.010$ & $9.258+/-4.332$ & -9.884 & 0.008 \\
\hline Eviya & Evi & 38 & 16 & 45 & $0.932+/-0.018$ & $9.135+/-4.297$ & -0.79 & 0.523 \\
\hline Ewondo & Ewd & 25 & 12 & 37 & $0.933+/-0.023$ & $9.933+/-4.701$ & 0.954 & 0.676 \\
\hline Ewondo & Ewo & 53 & 39 & 54 & $0.983+/-0.008$ & $10.162+/-4.716$ & -20.307 & 0.000 \\
\hline Fang & $\mathrm{Fac}$ & 39 & 27 & 45 & $0.965+/-0.015$ & $9.501+/-4.454$ & -9.457 & 0.006 \\
\hline Fang & Fag & 66 & 36 & 55 & $0.971+/-0.009$ & $8.878+/-4.145$ & -12.994 & 0.005 \\
\hline Fali & Fal & 42 & 27 & 43 & $0.978+/-0.009$ & $8.197+/-3.878$ & -9.731 & 0.003 \\
\hline Fulbec & Fuc & 34 & 26 & 36 & $0.975+/-0.016$ & $6.674+/-3.228$ & -14.831 & 0.001 \\
\hline Galoa & Gal & 51 & 27 & 56 & $0.965+/-0.011$ & $9.001+/-4.214$ & -6.128 & 0.045 \\
\hline Eshira & Gis & 40 & 25 & 53 & $0.970+/-0.012$ & $10.077+/-4.703$ & -5.839 & 0.041 \\
\hline Akele & Kel & 48 & 35 & 54 & $0.985+/-0.008$ & $9.811+/-4.571$ & -16.756 & 0.000 \\
\hline Kota & Kot & 56 & 32 & 59 & $0.967+/-0.010$ & $10.562+/-4.885$ & -8.279 & 0.022 \\
\hline Makina & Mak & 45 & 27 & 51 & $0.962+/-0.015$ & $9.306+/-4.356$ & -7.284 & 0.020 \\
\hline Ndumu & $\mathrm{Ndu}$ & 39 & 26 & 53 & $0.973+/-0.012$ & $9.417+/-4.417$ & -8.013 & 0.010 \\
\hline Ngoumba & $\mathrm{NgO}$ & 44 & 36 & 52 & $0.990+/-0.007$ & $8.973+/-4.213$ & -23.106 & 0.000 \\
\hline Ngumba & $\mathrm{Ngu}$ & 88 & 43 & 57 & $0.969+/-0.007$ & $10.081+/-4.655$ & -14.1 & 0.003 \\
\hline Nzebi & Nze & 63 & 42 & 64 & $0.976+/-0.001$ & $8.955+/-4.181$ & -22.917 & 0.000 \\
\hline Obamba & Oba & 47 & 35 & 63 & $0.988+/-0.007$ & $9.741+/-4.542$ & -17.487 & 0.000 \\
\hline Orungu & Oru & 20 & 16 & 40 & $0.973+/-0.025$ & $10.895+/-5.173$ & -3.53 & 0.086 \\
\hline Punu & Pun & 52 & 35 & 64 & $0.982+/-0.007$ & $9.123+/-4.265$ & -15.937 & 0.000 \\
\hline Sanga & San & 30 & 21 & 36 & $0.970+/-0.016$ & $8.970+/-4.250$ & -5.877 & 0.022 \\
\hline Shake & Sha & 51 & 34 & 57 & $0.973+/-0.011$ & $10.194+/-4.733$ & -13.011 & 0.000 \\
\hline
\end{tabular}


Table 1 Intra-population summary statistics (Continued)

\begin{tabular}{|c|c|c|c|c|c|c|c|c|}
\hline Tali & Tal & 20 & 15 & 34 & $0.974+/-0.022$ & $6.695+/-3.296$ & -4.77 & 0.025 \\
\hline Ateke & Tek & 54 & 39 & 53 & $0.985+/-0.007$ & $9.088+/-4.248$ & -21.957 & 0.000 \\
\hline Tsogo & Tso & 64 & 33 & 56 & $0.961+/-0.010$ & $9.058+/-4.224$ & -9.5 & 0.010 \\
\hline Tupuri & Tup & 26 & 24 & 53 & $0.994+/-0.013$ & $7.917+/-3.804$ & -15.876 & 0.000 \\
\hline \multicolumn{9}{|c|}{ WEST-CENTRAL } \\
\hline Afaha Obong & Ana & 37 & 31 & 45 & $0.989+/-0.009$ & $7.137+/-3.424$ & -22.296 & 0.000 \\
\hline Ediene Abak & Ane & 26 & 23 & 33 & $0.988+/-0.016$ & $6.252+/-3.067$ & -16.121 & 0.000 \\
\hline Ikot Obioma & Ani & 44 & 37 & 48 & $0.991+/-0.007$ & $7.246+/-3.451$ & -25.019 & 0.000 \\
\hline Efut 1 & Efe & 49 & 44 & 58 & $0.996+/-0.005$ & $8.550+/-4.021$ & -24.807 & 0.000 \\
\hline Efut 2 & Efi & 48 & 39 & 52 & $0.991+/-0.006$ & $7.566+/-3.593$ & -24.958 & 0.000 \\
\hline Uwanse & Efo & 48 & 40 & 55 & $0.988+/-0.009$ & $7.779+/-3.686$ & -24.925 & 0.000 \\
\hline Akampka & Eka & 17 & 17 & 33 & $1.000+/-0.020$ & $7.698+/-3.775$ & -11.201 & 0.000 \\
\hline Calabar & Ekc & 28 & 24 & 44 & $0.989+/-0.012$ & $7.259+/-3.504$ & -14.509 & 0.000 \\
\hline Ikom & Eki & 38 & 33 & 51 & $0.991+/-0.009$ & $7.368+/-3.524$ & -24.653 & 0.000 \\
\hline Akampka & Ekn & 50 & 47 & 53 & $0.997+/-0.005$ & $7.169+/-3.418$ & -25.03 & 0.000 \\
\hline Enchi1 & Ghe & 20 & 19 & 35 & $0.995+/-0.018$ & $7.400+/-3.612$ & -11.922 & 0.000 \\
\hline Enchi & Ghf & 59 & 46 & 53 & $0.988+/-0.006$ & $6.965+/-3.321$ & -25.054 & 0.000 \\
\hline Ho & Ghh & 87 & 54 & 48 & $0.984+/-0.005$ & $6.294+/-3.015$ & -25.138 & 0.000 \\
\hline Kibi & Ghk & 51 & 42 & 53 & $0.989+/-0.007$ & $6.452+/-3.104$ & -25.17 & 0.000 \\
\hline Afaha Eket & lae & 50 & 36 & 48 & $0.984+/-0.007$ & $7.234+/-3.446$ & -23.108 & 0.000 \\
\hline Awa & Iba & 28 & 24 & 38 & $0.987+/-0.014$ & $7.241+/-3.496$ & -14.54 & 0.000 \\
\hline Itam & Ibi & 48 & 42 & 51 & $0.994+/-0.006$ & $7.113+/-3.396$ & -25.042 & 0.000 \\
\hline Oku & lbo & 48 & 39 & 50 & $0.988+/-0.008$ & $7.662+/-3.635$ & -24.939 & 0.000 \\
\hline Idoma & Ido & 37 & 28 & 49 & $0.979+/-0.012$ & $7.096+/-3.407$ & -15.86 & 0.000 \\
\hline Edienne Ikono & lei & 49 & 43 & 55 & $0.995+/-0.005$ & $7.985+/-3.774$ & -24.89 & 0.000 \\
\hline Igala & lga & 41 & 35 & 45 & $0.990+/-0.008$ & $6.754+/-3.249$ & -24.98 & 0.000 \\
\hline Calabar & $\lg c$ & 96 & 69 & 56 & $0.988+/-0.005$ & $7.435+/-3.506$ & -24.865 & 0.000 \\
\hline Enugu & Ige & 54 & 45 & 58 & $0.992+/-0.006$ & $8.117+/-3.826$ & -24.863 & 0.000 \\
\hline Nenwe & $\lg n$ & 50 & 38 & 50 & $0.981+/-0.011$ & $7.739+/-3.666$ & -24.652 & 0.000 \\
\hline Ntan Ibiono & Ini & 50 & 38 & 47 & $0.988+/-0.007$ & $7.177+/-3.421$ & -24.965 & 0.000 \\
\hline Nnung Ndem & Inn & 50 & 39 & 53 & $0.989+/-0.006$ & $7.962+/-3.763$ & -24.832 & 0.000 \\
\hline Oku-lboku & loi & 50 & 36 & 41 & $0.985+/-0.007$ & $7.225+/-3.442$ & -23.131 & 0.000 \\
\hline Obong Itam & Ita & 50 & 44 & 45 & $0.994+/-0.005$ & $7.329+/-3.488$ & -24.999 & 0.000 \\
\hline
\end{tabular}


Table 1 Intra-population summary statistics (Continued)

\begin{tabular}{|c|c|c|c|c|c|c|c|c|}
\hline Ukpom Ette & lue & 50 & 42 & 52 & $0.993+/-0.005$ & $7.701+/-3.650$ & -24.935 & 0.000 \\
\hline Western Nsit & Iwn & 36 & 26 & 44 & $0.975+/-0.014$ & $7.187+/-3.449$ & -12.604 & 0.000 \\
\hline Afaha Okpo & Oao & 28 & 23 & 38 & $0.987+/-0.013$ & $6.598+/-3.212$ & -13.445 & 0.000 \\
\hline Afaha Ukwong & Oau & 70 & 47 & 48 & $0.987+/-0.005$ & $7.409+/-3.505$ & -24.943 & 0.000 \\
\hline Tiv & Tiv & 51 & 43 & 55 & $0.992+/-0.006$ & $8.042+/-3.797$ & -24.88 & 0.000 \\
\hline Yoruba & Yor & 34 & 31 & 42 & $0.995+/-0.009$ & $6.371+/-3.099$ & -25.145 & 0.000 \\
\hline \multicolumn{9}{|l|}{ WEST } \\
\hline Gb1* & Gb1 & 50 & 37 & 47 & $0.989+/-0.006$ & $6.693+/-3.211$ & -24.988 & 0.000 \\
\hline Gb2* & Gb2 & 22 & 15 & 35 & $0.957+/-0.028$ & $8.216+/-3.961$ & -2.846 & 0.095 \\
\hline Gb3* & Gb3 & 62 & 50 & 51 & $0.992+/-0.005$ & $8.703+/-4.072$ & -24.756 & 0.000 \\
\hline Gb4* & Gb4 & 77 & 49 & 56 & $0.978+/-0.007$ & $7.289+/-3.450$ & -24.946 & 0.000 \\
\hline Gb5* & Gb5 & 77 & 49 & 57 & $0.976+/-0.008$ & $7.378+/-3.488$ & -24.93 & 0.000 \\
\hline Gb6* & Gb6 & 58 & 47 & 61 & $0.987+/-0.008$ & $7.685+/-3.634$ & -24.924 & 0.000 \\
\hline $\mathrm{Gb}^{*}$ & Gb7 & 26 & 20 & 42 & $0.969+/-0.022$ & $7.520+/-3.628$ & -7.982 & 0.000 \\
\hline Limba & Lim & 67 & 48 & 56 & $0.984+/-0.007$ & $6.728+/-3.211$ & -25.085 & 0.000 \\
\hline Loko & Lok & 29 & 27 & 45 & $0.988+/-0.011$ & $8.393+/-3.989$ & -15.409 & 0.010 \\
\hline Mandenka & Mad & 78 & 25 & 44 & $0.935+/-0.012$ & $6.226+/-2.989$ & -4.59 & 0.070 \\
\hline Mende & Men & 55 & 49 & 59 & $0.996+/-0.004$ & $8.475+/-3.980$ & -24.805 & 0.000 \\
\hline Serer & Ser & 23 & 18 & 36 & $0.968+/-0.026$ & $7.533+/-3.650$ & -6.678 & 0.000 \\
\hline Temne & Tem & 122 & 77 & 71 & $0.989+/-0.003$ & $7.787+/-3.651$ & -24.715 & 0.000 \\
\hline Woloff & Wol & 48 & 39 & 44 & $0.991+/-0.006$ & $7.622+/-3.618$ & -24.947 & 0.000 \\
\hline
\end{tabular}

$\mathrm{N}$, number of individuals for each population; $\mathrm{K}$, number of haplotypes; $\mathrm{S}$, number of segregating sites; HD, haplotype diversity; MNPD, mean number of pairwise differences; $F s$, Fu's statistic; $\mathrm{p}$, statistical significance (in italics, non-significant). In bold, populations typed in the present study; for additional information, refer to Additional file 1: Table S1. For populations labelled with * please refer to Additional file 1: Tables S1 and original publication for further details. 
Akampka, and MNPD between 6.029 in Sefwi-Wiawso and 10.895 in Orungu. Fu's Fs neutrality test provided large significant negative values for the great majority of populations analysed. Only 7 out of 85 departed from this pattern, five of which were located between Gabon and Congo, the other two being settled in Western Africa (Table 1 and Additional file 1: Table S1).
Pairwise genetic distances were calculated among all populations and the matrix represented in a MDS plot, shown in Figure 1. The two-dimensional plot presented a stress value of 0.122 , which is lower than the $1 \%$ cutoff value of 0.390 ascertained in Sturrock and Rocha (2000) [42]. Populations from Western, Central-Western and Central African regions, are well recognizable in the

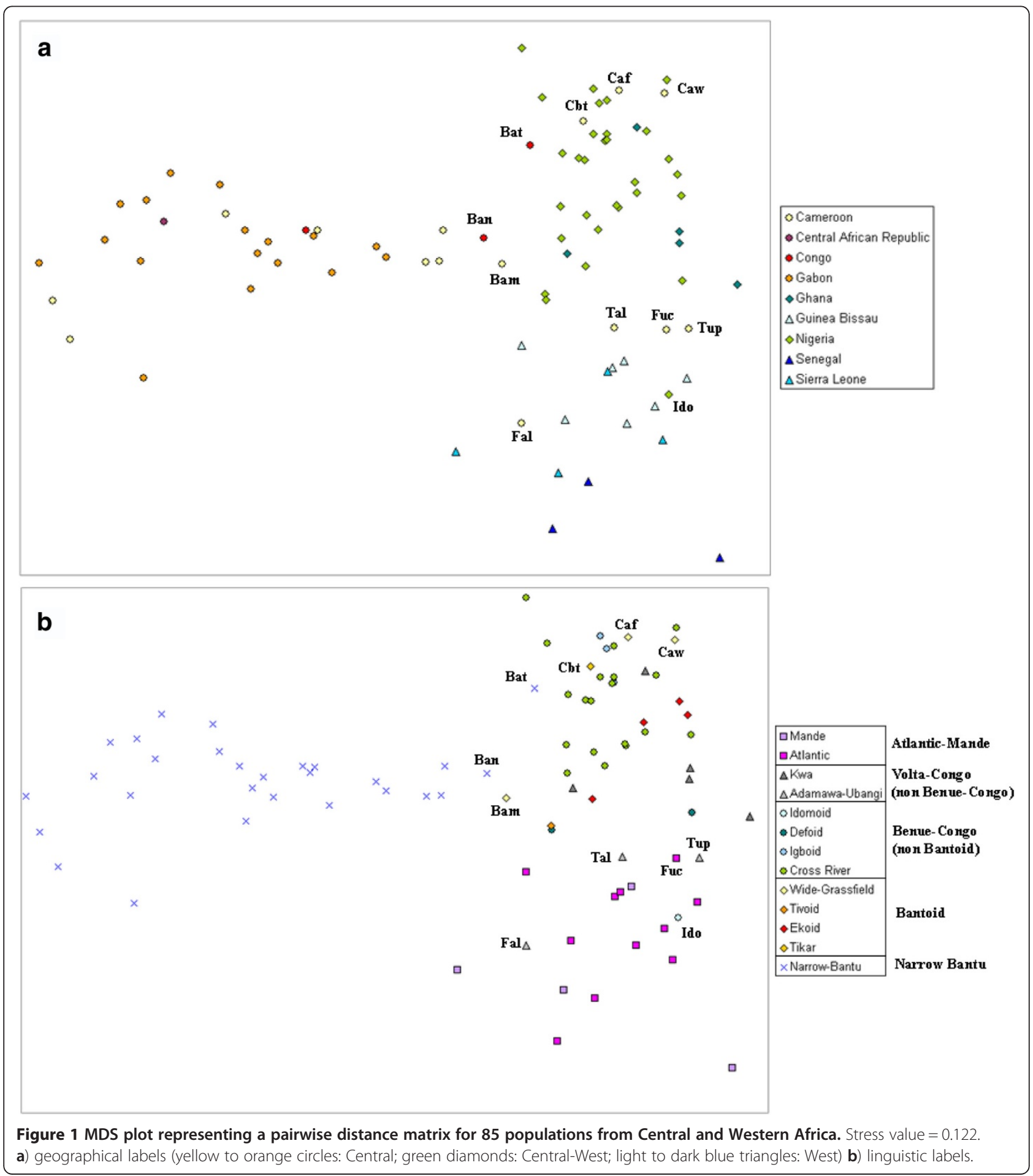


Table 2 Assignation to DAPC clusters and habitat (s, savannah, and r, rainforest, based on reconstructed map of biomass from Baccini et al., (2008),[43]; see Methods) for each population with the relative Fu's statistic (Fs) values (in italics, non-significant) and the Fs mean value per cluster

\begin{tabular}{|c|c|c|c|c|c|}
\hline Population & Country & DAPC cluster & Habitat & Fs & Mean Fs \\
\hline Ghe & Ghana & 1 & $\mathrm{~s}$ & -11.922 & \\
\hline Ghf & Ghana & 1 & s & -25.054 & \\
\hline Ghh & Ghana & 1 & s & -25.138 & \\
\hline Ghk & Ghana & 1 & s & -25.170 & \\
\hline Ghs & Ghana & 1 & s & -12.390 & -21.832 \\
\hline $\mathrm{Ibi}$ & Nigeria & 1 & $\mathrm{~s}$ & -25.042 & \\
\hline Iga & Nigeria & 1 & s & -24.979 & \\
\hline Ini & Nigeria & 1 & $\mathrm{~s}$ & -24.965 & \\
\hline Ben & Gabon & 2 & $r$ & -4.526 & \\
\hline Evi & Gabon & 2 & $r$ & -0.790 & \\
\hline Ewd & Cameroon & 2 & s & 0.954 & \\
\hline $\mathrm{Fac}$ & Cameroon & 2 & $r$ & -9.457 & \\
\hline Gis & Gabon & 2 & $r$ & -5.839 & \\
\hline Kel & Gabon & 2 & $r$ & -16.756 & -7.388 \\
\hline Kot & Gabon & 2 & $r$ & -8.279 & \\
\hline Mak & Gabon & 2 & $r$ & -7.284 & \\
\hline $\mathrm{Ngu}$ & Cameroon & 2 & $r$ & -14.100 & \\
\hline Oru & Gabon & 2 & $r$ & -3.530 & \\
\hline San & Central African Republic & 2 & $\mathrm{~s}$ & -5.877 & \\
\hline Sha & Gabon & 2 & $r$ & -13.011 & \\
\hline Ana & Nigeria & 3 & s & -22.296 & \\
\hline Ane & Nigeria & 3 & s & -16.121 & \\
\hline Ani & Nigeria & 3 & s & -25.019 & \\
\hline$\overline{C a f}$ & Cameroon & 3 & s & -24.730 & \\
\hline Caw & Cameroon & 3 & $\mathrm{~s}$ & -24.782 & \\
\hline $\mathrm{Cbt}$ & Cameroon & 3 & s & -9.603 & \\
\hline Efe & Nigeria & 3 & s & -24.807 & \\
\hline Efi & Nigeria & 3 & s & -24.958 & \\
\hline Efo & Nigeria & 3 & s & -24.925 & \\
\hline Eka & Nigeria & 3 & $\mathrm{~s}$ & -11.201 & \\
\hline Ekc & Nigeria & 3 & s & -14.509 & -21.607 \\
\hline Eki & Nigeria & 3 & s & -24.653 & \\
\hline Ekn & Nigeria & 3 & s & -25.030 & \\
\hline
\end{tabular}


Table 2 Assignation to DAPC clusters and habitat (s, savannah, and r, rainforest, based on reconstructed map of biomass from Baccini et al., (2008),[43]; see Methods) for each population with the relative Fu's statistic (Fs) values (in italics, non-significant) and the Fs mean value per cluster (Continued)

\begin{tabular}{|c|c|c|c|c|c|}
\hline lae & Nigeria & 3 & s & -23.108 & \\
\hline Iba & Nigeria & 3 & s & -14.540 & \\
\hline Ibo & Nigeria & 3 & s & -24.939 & \\
\hline lei & Nigeria & 3 & s & -24.890 & \\
\hline $\lg c$ & Nigeria & 3 & s & -24.865 & \\
\hline lge & Nigeria & 3 & $\mathrm{~s}$ & -24.863 & \\
\hline $\operatorname{lgn}$ & Nigeria & 3 & $\mathrm{~s}$ & -24.652 & \\
\hline $\operatorname{lnn}$ & Nigeria & 3 & $\mathrm{~s}$ & -24.832 & \\
\hline loi & Nigeria & 3 & $\mathrm{~s}$ & -23.131 & \\
\hline Ita & Nigeria & 3 & s & -24.999 & \\
\hline lue & Nigeria & 3 & $\mathrm{~s}$ & -24.935 & \\
\hline Iwn & Nigeria & 3 & s & -12.604 & \\
\hline Oao & Nigeria & 3 & s & -13.445 & \\
\hline$\overline{\mathrm{Oau}}$ & Nigeria & 3 & s & -24.943 & \\
\hline Bak & Cameroon & 4 & $r$ & -17.339 & \\
\hline Bam & Cameroon & 4 & $\mathrm{~s}$ & -22.157 & \\
\hline Ban & Congo & 4 & $r$ & -24.766 & \\
\hline Bas & Cameroon & 4 & $r$ & -24.685 & -19.009 \\
\hline Bat & Congo & 4 & $r$ & -5.416 & \\
\hline Fal & Cameroon & 4 & $\mathrm{~s}$ & -9.731 & \\
\hline $\mathrm{Ngo}$ & Cameroon & 4 & $r$ & -23.106 & \\
\hline Tiv & Nigeria & 4 & s & -24.877 & \\
\hline$\overline{G b 5}$ & Guinea Bissau & 5 & s & -24.930 & \\
\hline Lok & Sierra Leone & 5 & s & -15.409 & \\
\hline Mad & Senegal & 5 & s & -4.590 & -16.893 \\
\hline Men & Sierra Leone & 5 & $\mathrm{~s}$ & -24.805 & \\
\hline Ser & Senegal & 5 & s & -6.678 & \\
\hline Wol & Senegal & 5 & $\mathrm{~s}$ & -24.947 & \\
\hline Fuc & Cameroon & 6 & $\mathrm{~s}$ & -14.831 & \\
\hline Gb1 & Guinea Bissau & 6 & s & -24.988 & \\
\hline Gb2 & Guinea Bissau & 6 & $\mathrm{~s}$ & -2.846 & \\
\hline Gb3 & Guinea Bissau & 6 & s & -24.756 & \\
\hline $\mathrm{Gb} 4$ & Guinea Bissau & 6 & s & -24.946 & \\
\hline$\overline{G b 6}$ & Guinea Bissau & 6 & s & -24.924 & -18.209 \\
\hline
\end{tabular}


Table 2 Assignation to DAPC clusters and habitat (s, savannah, and r, rainforest, based on reconstructed map of biomass from Baccini et al., (2008),[43]; see Methods) for each population with the relative Fu's statistic (Fs) values (in italics, non-significant) and the Fs mean value per cluster (Continued)

\begin{tabular}{|c|c|c|c|c|c|}
\hline Gb7 & Guinea Bissau & 6 & s & -7.982 & \\
\hline Ido & Nigeria & 6 & s & -15.857 & \\
\hline$\underline{\operatorname{Lim}}$ & Sierra Leone & 6 & $\mathrm{~s}$ & -25.085 & \\
\hline Tal & Cameroon & 6 & s & -4.770 & \\
\hline Tem & Sierra Leone & 6 & s & -24.715 & \\
\hline Tup & Cameroon & 6 & $\mathrm{~s}$ & -15.876 & \\
\hline Yor & Nigeria & 6 & $\mathrm{~s}$ & -25.145 & \\
\hline Bet & Congo & 7 & $r$ & -9.449 & \\
\hline Dum & Gabon & 7 & $r$ & -9.884 & \\
\hline Ewo & Cameroon & 7 & $r$ & -20.307 & \\
\hline Fag & Gabon & 7 & $r$ & -12.994 & \\
\hline Gal & Gabon & 7 & $r$ & -6.128 & \\
\hline $\mathrm{Ndu}$ & Gabon & 7 & $r$ & -8.013 & -14.052 \\
\hline Nze & Gabon & 7 & $r$ & -22.917 & \\
\hline$\overline{O b a}$ & Gabon & 7 & $r$ & -17.487 & \\
\hline Pun & Gabon & 7 & $r$ & -15.937 & \\
\hline Tek & Gabon & 7 & $r$ & -21.957 & \\
\hline Tso & Gabon & 7 & $r$ & -9.500 & \\
\hline
\end{tabular}

For abbreviations and additional information, refer to Additional file 1: Table S1. 


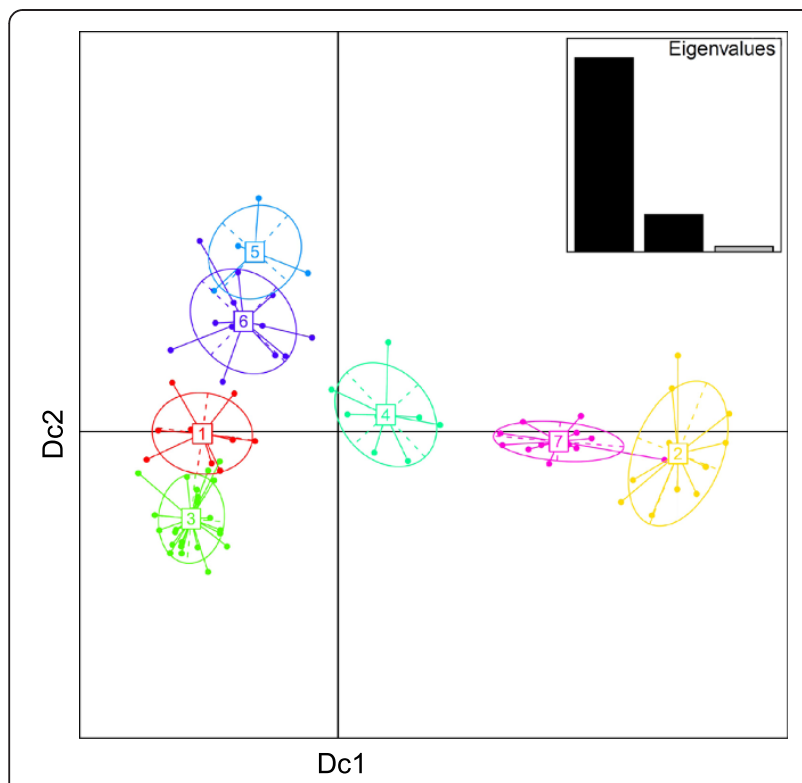

Figure 2 Scatterplot of the populations' coordinates onto the discriminant functions $\mathbf{1}$ and $\mathbf{2}$. Ellipses of dispersion are proportional to the internal variance of the clusters. In the right upper corner, the eigenvalues for discriminant functions 1 and 2 are reported. See Figure 4 for a map of the populations, labelled according to cluster assignation.

MDS plot (Figure 1a and Additional file 1: Table S1), with the latter showing higher average genetic distances. As expected, this geographic trend is no longer observed at single-country level, underlining the nonrepresentativeness of African political boundaries in defining population units. In particular, North Cameroonian populations (Tali, Tupuri and FulbeC) group together with Western populations from Senegal and Sierra-Leone, while Western Cameroonians (Foumban, Wum, Bankim, and, to a lesser extent, Bamileke) are closer to Nigerians and the other Western-Central groups. Both Bateke populations from Congo appeared to be closer to Central Western groups than Central ones. Finally, Idoma from Nigeria present lower average genetic distances from Western African populations than from Western Central, despite their geographical proximity (Additional file 2: Table S2).

From a linguistic point of view (Figure 1b), the different families of the Niger-Congo phylum already show a geographically structured distribution, but, at a more refined level of classification, linguistic genealogical relationships do not correlate with genetic distances (see Additional file 3: Figure S1b).

\section{Population genetic structure}

The Bayesian Information Criterion (BIC; Additional file 4: Figure S2a) established that 7 was the best number of clusters to describe the genetic structure of the dataset analysed: cluster assignations are presented in Table 2 and Additional file 4: Figure S2b. The a.score was 0.752, which means that the probability of re-assignment of populations to true clusters is three times higher than to randomly permuted clusters. Some ambiguity was observed in the population clustering but this mainly concerned pairs of

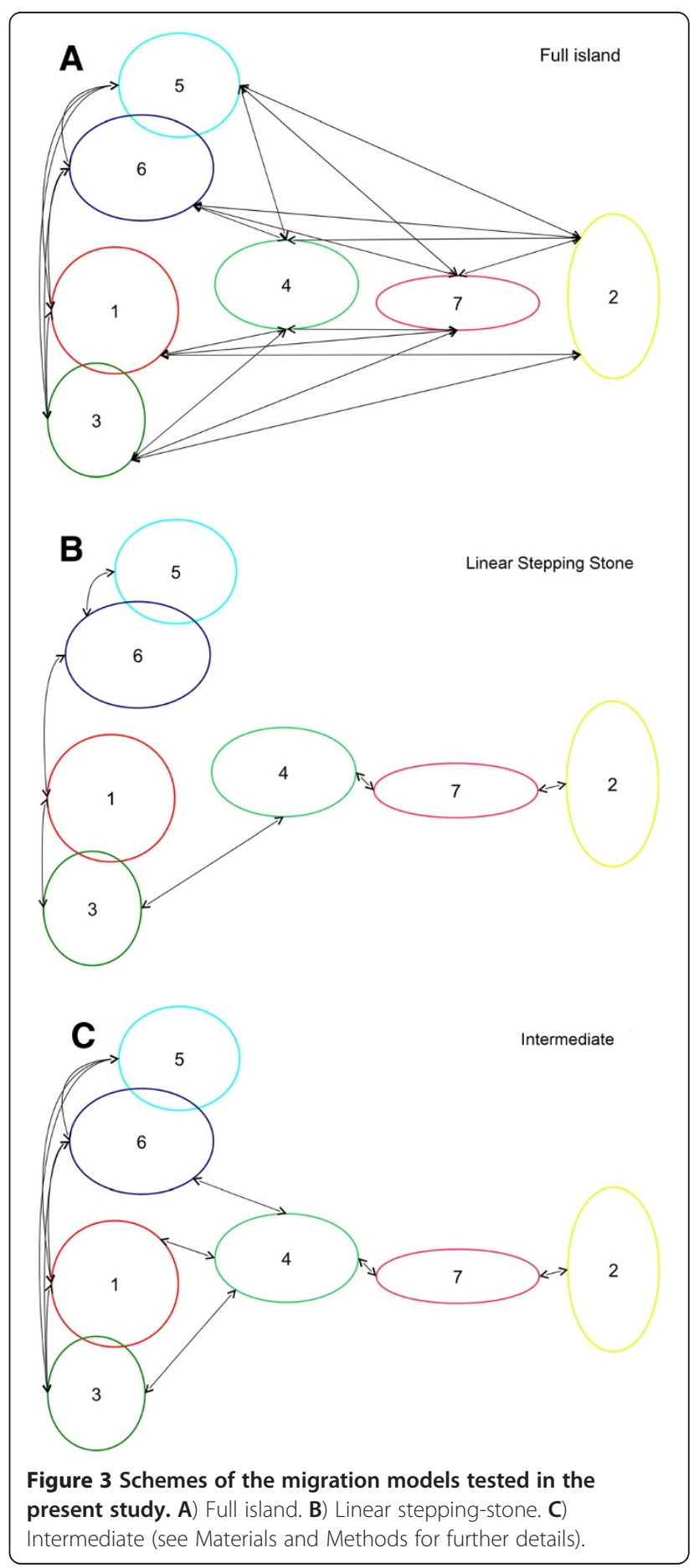


Table 3 Log Bayes Factor (LBF) calculated to compare the three migration models

\begin{tabular}{|c|c|c|c|c|c|c|c|c|c|}
\hline \multicolumn{10}{|l|}{ SUB1 } \\
\hline LBF (MA | MB) & -714.0927 & -868.8034 & -959.4728 & -821.0730 & -761.8231 & -826.2525 & -873.9830 & -847.3129 & -954.2933 \\
\hline $\mathrm{LBF}(\mathrm{MB} \mid \mathrm{MC})$ & 327.0815 & 360.9551 & 391.0639 & 253.9748 & 434.0619 & 385.8844 & 366.1346 & 439.2414 & 366.1347 \\
\hline LBF (MA | MC) & -387.0111 & -507.8483 & -568.4088 & -460.1179 & -434.7416 & -435.1886 & -482.9190 & -520.2314 & -593.3381 \\
\hline \multicolumn{10}{|l|}{ SUB2 } \\
\hline LBF (MA | MB) & -1018.3370 & -931.4481 & -1025.5500 & -914.7968 & -1034.9890 & -967.9367 & -984.5880 & -1075.9510 & -972.4104 \\
\hline LBF (MB | MC) & 566.1677 & 578.1712 & 629.6136 & 681.7117 & 462.6272 & 680.0142 & 1388.8972 & 576.4737 & 631.3111 \\
\hline LBF (MA | MC) & -452.1696 & -353.2769 & -395.9367 & -336.6256 & -468.8209 & -338.3231 & -354.9744 & -509.7832 & -394.2400 \\
\hline \multicolumn{10}{|l|}{ SUB3 } \\
\hline LBF (MA | MB) & -820.9318 & -952.3143 & -871.5584 & -983.2491 & -789.9969 & -907.2188 & -785.2714 & -947.5887 & -876.2840 \\
\hline $\mathrm{LBF}(\mathrm{MB} \mid \mathrm{MC})$ & 285.2062 & 567.2732 & 513.2826 & 404.9559 & 447.5236 & 426.9956 & 371.4934 & 589.3129 & 491.2430 \\
\hline LBF (MA | MC) & -535.7255 & -385.0410 & -358.2758 & -415.9758 & -504.7906 & -393.9361 & -500.0651 & -380.3154 & -363.0013 \\
\hline \multicolumn{10}{|l|}{ SUB4 } \\
\hline LBF (MA | MB) & -729.1903 & -921.9774 & -873.2387 & -843.5139 & -807.6538 & -870.2610 & -948.7245 & -732.1681 & -846.4916 \\
\hline LBF (MB | MC) & 130.8856 & 274.7434 & 287.9298 & 160.4199 & 245.2092 & 146.8591 & 261.1827 & 271.9562 & 301.4905 \\
\hline LBF (MA | MC) & -598.3048 & -647.2339 & -585.3090 & -568.7705 & -676.7682 & -582.3313 & -660.7947 & -601.2825 & -571.7482 \\
\hline \multicolumn{10}{|l|}{ SUB5 } \\
\hline LBF (MA | MB) & -806.5704 & -826.3470 & -819.5543 & -815.0049 & -817.9125 & -812.2241 & -823.5663 & -813.9005 & -822.3351 \\
\hline LBF (MB | MC) & 521.3028 & 616.3976 & 414.1053 & 607.9631 & 529.7374 & 416.8861 & 408.4515 & 526.9566 & 613.6168 \\
\hline $\operatorname{LBF}(M A \mid M C)$ & -285.2675 & -209.9494 & -405.4490 & -198.6073 & -296.6097 & -398.1189 & -409.4610 & -292.5977 & -205.9374 \\
\hline
\end{tabular}

Each sub-sampling was run three times for each model allowing 27 pairs of model comparisons based on the thermodynamic integration value. MA is the full island model, MB the stepping-stone model and MC is the intermediate model. An LBF $>2$ indicates a higher probability for the numerator model; values $<2$ indicate the contrary.

Table 4 Theta and $M$ values estimated for MB (stepping-stone)

\begin{tabular}{|c|c|c|c|c|c|c|c|c|}
\hline & \multicolumn{8}{|c|}{ Averaged values of theta and $M$} \\
\hline & & $M$ inco & & & & & & \\
\hline & $\theta$ & Clu 2 & Clu 7 & Clu 4 & Clu 3 & Clu 1 & Clu 6 & Clu 5 \\
\hline \multirow[t]{16}{*}{ M outgoing } & Clu 2 & 0.0198 & 0.2500 & - & - & - & - & - \\
\hline & Clu 7 & 0.2500 & 0.0269 & 5.2500 & - & - & - & - \\
\hline & Clu 4 & - & 10.6500 & 0.0129 & 7.3500 & - & - & - \\
\hline & Clu 3 & - & - & 4.8500 & 0.0198 & 5.1500 & - & - \\
\hline & Clu 1 & - & - & - & 8.0500 & 0.0127 & 0.2500 & - \\
\hline & Clu 6 & - & - & - & - & 0.2500 & 0.0254 & 2.7500 \\
\hline & Clu 5 & - & - & - & - & - & 11.050 & 0.0067 \\
\hline & \multicolumn{8}{|c|}{ s. d. of theta and $\mathrm{M}$ values } \\
\hline & $\theta$ & Clu 2 & Clu 7 & Clu 4 & Clu 3 & Clu 1 & Clu 6 & Clu 5 \\
\hline & Clu 2 & 0.0003 & 0.0000 & - & - & - & - & - \\
\hline & Clu 7 & 0.0000 & 0.0005 & 0.3535 & - & - & - & - \\
\hline & Clu 4 & - & 0.2236 & 0.0003 & 0.2236 & - & - & - \\
\hline & Clu 3 & - & - & 0.2236 & 0.0000 & 0.4183 & - & - \\
\hline & Clu 1 & - & - & - & 0.2738 & 0.0004 & 0.0000 & - \\
\hline & Clu 6 & - & - & - & - & 0.0000 & 0.0005 & 0.4183 \\
\hline & Clu 5 & - & - & - & - & - & 0.2738 & 0.0002 \\
\hline
\end{tabular}

Values of thetas are reported on the diagonal. Direction of migration is represented as outgoing from the clusters in row and incoming into the clusters in column (e.g. $\mathrm{M}$ is 5.2500 in the direction 7 - > 4, and 10.6500 in the direction 4 - > 7); "-" states for migration flows not allowed. 
Table 5 Averaged values of first and last percentile of the distributions of Theta and $M$ with standard deviations calculated combining all the runs for the stepping-stone model

\begin{tabular}{lllllll}
\hline & $\mathbf{2 . 5} \%$ & s.d. & mode & s.d. & $\mathbf{9 7 . 5} \%$ & s.d. \\
\hline$\theta$ clust2 & 0.0055 & 0.0003 & 0.0198 & 0.0003 & 0.0390 & 0.0012 \\
$\theta$ clust7 & 0.0103 & 0.0004 & 0.0269 & 0.0005 & 0.0527 & 0.0025 \\
$\theta$ clust4 & 0.0000 & 0.0000 & 0.0129 & 0.0003 & 0.0301 & 0.0011 \\
$\theta$ clust3 & 0.0058 & 0.0002 & 0.0198 & 0.0000 & 0.0386 & 0.0019 \\
$\theta$ clust1 & 0.0000 & 0.0000 & 0.0127 & 0.0004 & 0.0308 & 0.0013 \\
$\theta$ clust6 & 0.0095 & 0.0005 & 0.0253 & 0.0005 & 0.0512 & 0.0023 \\
$\theta$ clust5 & 0.0000 & 0.0000 & 0.0067 & 0.0002 & 0.0194 & 0.0017 \\
M7->2 & 0.0000 & 0.0000 & 0.2500 & 0.0000 & 10.0000 & 0.0000 \\
M2->7 & 0.0000 & 0.0000 & 0.2500 & 0.0000 & 10.5000 & 0.3535 \\
M4->7 & 0.0000 & 0.0000 & 10.6500 & 0.2236 & 22.2000 & 0.5700 \\
M7->4 & 0.0000 & 0.0000 & 5.2500 & 0.3535 & 15.1000 & 0.2236 \\
M3->4 & 0.0000 & 0.0000 & 4.8500 & 0.2236 & 14.5000 & 0.0000 \\
M4->3 & 0.0000 & 0.0000 & 7.3500 & 0.2236 & 17.2000 & 0.2738 \\
M1->3 & 0.0000 & 0.0000 & 8.0500 & 0.2739 & 17.8000 & 0.4472 \\
M3->1 & 0.0000 & 0.0000 & 5.1500 & 0.4183 & 15.2000 & 0.2738 \\
M6->1 & 0.0000 & 0.0000 & 0.2500 & 0.0000 & 10.4000 & 0.4183 \\
M1->6 & 0.0000 & 0.0000 & 0.2500 & 0.0000 & 9.7000 & 0.2738 \\
M5->6 & 0.0000 & 0.0000 & 11.0500 & 0.2739 & 22.4000 & 0.8944 \\
M6->5 & 0.0000 & 0.0000 & 2.7500 & 0.4183 & 11.8000 & 0.2738 \\
\hline & & & & & &
\end{tabular}

close groups (mostly $3-1$; to a much lower extent $2-7$ and 5-6, see Additional file 4: Figure S2b).

As shown in the bi-dimensional plot, the 7 clusters were distributed according to a geographical pattern (Figure 2). In fact, the first discriminant function separated clusters 4, 7 and 2 (including most of the Central groups) from clusters 5, 6, 1 and 3 . The second function separated these last four into two clearly distinguishable groups, a Western (clusters 5 and 6) and a WesternCentral one (clusters 1 and 3). The third discriminant function slightly separated cluster 4 and 5 and presented very similar values for the rest (data not shown).

Most clusters were found to group populations that are geographically close together, with few exceptions (see Table 2). The variance of the geographic distances among clusters was times higher than within cluster $(\mathrm{F}=28.376, \mathrm{p}=$ 0.000 ). Clusters 2,4 and 7 are composed mainly by populations inhabiting the rainforest areas, starting from Central Cameroon (Table 2, [43]). The most heterogeneous among them is cluster 4 presenting two populations living in Central-North Cameroon (Bam and Fal) and one population from Nigeria (Tiv). Cluster 6 was the less geographically homogeneous, including two populations from Nigeria (Yoruba and Idoma) and the three nomadic groups from north Cameroon (Tali, Tupuri and FulbeC) along with Western Africans. On the other hand, the ellipses of dispersion indicated that clusters 3 and 7 , even though they account for the highest number of populations, had lower internal variances. This is probably due to the fact that they include the geographical areas with the densest sampling coverage, which results in a higher number of genetically more closely related populations.

Summary statistics calculated for the seven clusters are reported in Additional file 5: Table S3. The MNPD was shown to increase (albeit not significantly) moving from clusters 4,7 and 2 to the rest. The minimum evolution phylogenetic trees also presented much longer branches and consequently higher divergence for the sequences belonging to cluster 2 and 7 in comparison with the others (Additional file 6: Figure S3). An AMOVA was performed on the rainforest (populations in clusters 4, 7 and 2) vs savannah groups (populations in clusters 5, 6, 1 and 3). The percentage of molecular variance among populations within the two groups was lower than among groups ( $2.54 \%$ vs $5.24 \%$, both $\mathrm{p}<0.001)$.

In addition, the Mantel test showed a low but statistically significant correlation between geographic and genetic distances for the whole sample $(r=0.296$; $p<0.001)$. When dividing the populations according to their habitat, geographic and genetic distances were highly correlated within the savannah region $(\mathrm{r}=0.609 ; \mathrm{p}<0.001)$, while the rainforest area seemed characterized by a weaker but still significant correlation between the parameters $(r=0.251 ; p<0.02)$. This trend was confirmed when plotting the linear regression for the genetic and geographic distances of the clusters in directions West to East (which implies cluster 5 as the starting point; Additional file 7: Figure S4a) and East to West (with cluster 2 as the point of origin; Additional file 7: Figure S4b). In the former case, the correlation between linear and genetic distances was significant at 0.05 level $(p$ value $=0.015)$ and stronger than in the latter $\left(R^{2}=0.73\right.$ vs $\left.\mathrm{R}^{2}=0.53\right)$ which was non-significant ( $p$ value $\left.=0.065\right)$.

Interestingly, cluster 2 included four populations with a non-significant value of Fu's statistics. When averaging this parameter among populations within each cluster, cluster 2 presented the least negative value $(-7.388)$, while the others ranged from a mean value of -14.052 to -21.832 (Table 2). The Wilcoxon Mann-Whitney test indicated that the two sets of Fu's values for the savannah and rainforest populations are likely to be drawn from two differing distributions $(\mathrm{p}$-value $=6.817 \mathrm{e}-06)$ the median values of the Fu's statistic being -24.794 and -9.499 respectively.

\section{Migration models and migration rates}

Three different migration patterns were tested through a Bayesian approach, including a full island (A), a linear 


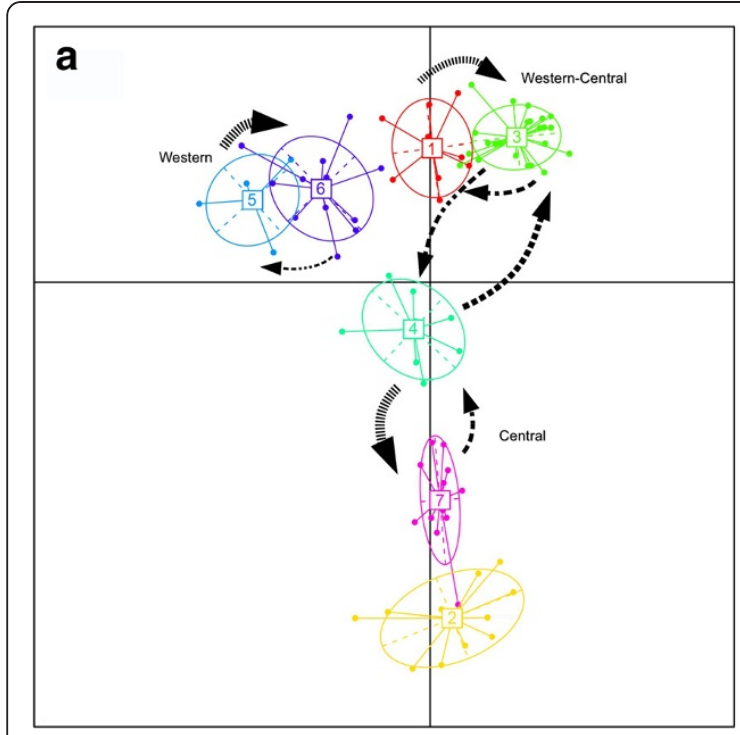

\section{b}

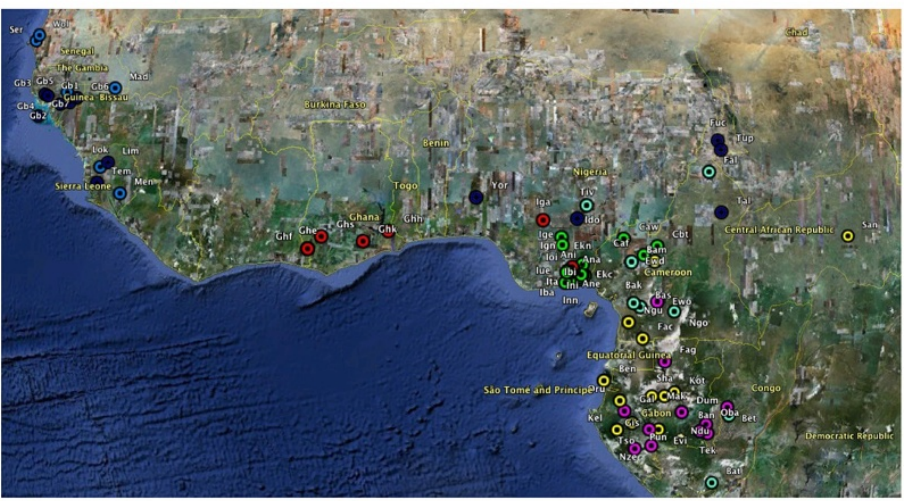

Figure 4 a) Results of the best migration model among DAPC-clustered populations. Arrows represent the migration rates $>0.01$ and their thickness is proportional to the original value. b) Map of the populations labelled according to the cluster analysis with the white lines representing discontinuities in gene flow (see Table 4).

stepping-stone (B) and an intermediate model (C; see Figure 3 for a schematic representation). The calculation of the LBF indicated model B as the best descriptor for the migration processes occurring in the region under study for all the five independent sub-samples (Table 3; see Material and Methods for details). The values of theta $(\Theta)$ and the migration rates $(\mathrm{M})$ obtained with model $\mathrm{B}$ were averaged for the fifteen independent runs and are reported in Table 4. Most of the posterior distributions showed normal shapes (Additional file 8: Figure S5) and the runs converged to very close values for all the parameters across the three runs (see standard deviation values in Tables 4 and 5). However, posteriors for the M parameters between clusters 7 and 2 and 1 and 6 were found to have a mode which was close to zero (see Table 4) and a constantly decreasing distribution when moving towards positive values. In these cases, the contribution of migrants exchanged to the observed variation could be considered as null (in italic in Table 4). Therefore, the resulting model is a stepping-stone with two main discontinuities, as described above, across the whole region (Figure 4).

Cluster 5 shows the lowest value of effective population size, having $\Theta=0.007$, while, for the remaining clusters, $\Theta$ values range between 0.013 and 0.027 (Table 4). Clusters 7, 3 and 6, which have the highest $\Theta$ values, presented the highest rates of immigrants ranging from 8 to $11 \%$. Cluster 4 is characterized by high flows both incoming and outgoing, while cluster 1 exchanges high rates of migrants with cluster 3 but no flow is retrieved with cluster 6 . Finally, cluster 5 is connected to cluster 6 through a high outgoing but low incoming migrant rate.
This is to be expected considering the lower $\Theta$ value compared to the other clusters (Table 4).

\section{Discussion}

Populations speaking languages belonging to the NigerCongo phylum have been the object of several studies, some of which aimed to assess the patterns associated with the diffusion of Bantu languages [13,21,28,29,44,45]. This is the phylum containing the highest number of languages worldwide and genealogical classification of its families is still under debate [46]. However, there is a consensus on the fact that western Atlantic and Mande are more ancient than central Benue-Congo and Bantu branches, while the emergence of Kordofanian remains unclear $[26,46,47]$. When autosomal variation is analysed, only a slight substructure among the populations belonging to the entire phylum is observed [25]. By increasing both the number of populations and the geographical coverage, we were able to obtain new insights into the relations among Niger-Congo speakers.

The populations included in our dataset speak languages belonging to several sub-branches of the $\mathrm{NC}$ family (see Additional file 3: Figure S1b) and are scattered through a vast area of sub-Saharan Africa, which mainly includes two habitats: the savannah and the rainforest. Roughly speaking, the first prevails in the region from Senegal to Northern Cameroon while the second characterizes most of the areas corresponding to Southern Cameroon, Gabon and Congo. Climatic studies have shown that after the phenomenon known as the Younger Dryas $(11.5 \pm 0.25$ ka B.P; $[48,49])$, the climatic conditions in the sub-Saharan region became less arid and the 
distribution and density of the rainforest have remained stable for the last $9.5 \mathrm{ky}$ [50]. The peopling of the subSaharan region is likely to have increased since then and the populations here considered have probably been in contact within the same time frame.

Given the shared traditional patrilocal habit of the populations under study, we were able to focus on mtDNA variation as the source of genetic information for microevolutionary inference. By combining a multivariate approach with the test of specific migration patterns, we were able to detect a complex structure among the populations under study, which seems to be better explained by the effect of local environmental factors rather than the internal linguistic complexity of the NC phylum.

After testing three migratory models (Figure 3), we observed that the stepping-stone model better describes the distribution of mtDNA variation throughout the whole region. This may indicate a general tendency of women to spread out from their villages with the intensity of the migration decreasing with distance, so that only neighbouring groups share common genetic variation. The isolation by distance (IBD) pattern observed in our sample is in agreement with previous studies which showed that geographic distances better explain genetic differences among human populations than ethnic affiliations [19,51].

Apart from this general indication, the analysis of mtDNA variation allowed us to identify two main groups quite clearly, with the rainforest populations being more structured and diverse than the savannah groups. In fact, the former populations are characterized by higher values of molecular measures of within-population diversity (see for example the MNPD in Table 1), larger genetic distances and phylogenetic trees with longer branches, and a lower proportion of different haplotypes (corresponding to Central in Table 1, and to clusters 2,7 and 4 in Figure 2). The analysis of genetic structure detected the main signal of differentiation in this group, separating clusters 4,2 and 7 from the others. The two groups also show a significant difference in the distribution of their Fs values, with rainforest populations showing a less negative average (one tailed $t$-test for mean comparison, $\mathrm{p}$-value $=2.3 \mathrm{e}-10$ ) as well as including 5 out of the 7 populations with non-significant Fs values (Table 1), suggesting a less important role of demographic expansions in their evolutionary history. The Fu's test, and other statistics relying on haplotype frequencies, were found to be more sensitive for detecting expansions on nonrecombining genomic regions than Tajima's D and other tests [52]. This signature of genetic drift could have been enhanced by the reduced effective population size of the mtDNA compared to autosomal loci, which however seems unlikely to have generated the non random genetic structure observed here.
The signature of IBD detected within the savannah region is higher than the one in the rainforest, and indicates, together with the observations of a lower degree of isolation among the former, that the migratory patterns are more straightforward to interpret in the savannah than in the forest. Therefore, we may conclude that although geographic factors have a role in both areas, for the savannah this can be simply described as a linear correlation between physical and genetic distances, while for the rainforest the role played by environmental factors is probably more complex. This conclusion highlights the usefulness of explicit geographic models in trying to understand human genetic diversity, which has been previously suggested by Ray and Excoffier (2009) [53].

As an important evolutionary consideration, we should take into account the possibility that differences in Fu's statistical values between savannah and rainforest could be also explained by the role of selection. However, although the worldwide distribution of mtDNA lineages has been proposed to be driven by selective processes related to temperature changes, the geographic region here analysed appears to be quite homogeneous for this putative temperature effect [54]. In future studies, researchers should consider that other climatic parameters which are different in the savannah and rainforest environments have yet to be explored.

Another caveat of the present study may be the a priori definition of population units, based on the sampling location and the languages spoken by the individuals. We are aware that such a definition may lead to an approximation in the estimate of the spatial distribution of allele frequencies, since each population is considered as a sampling point. In the present case, we believe that, despite the vast geographical area covered by our dataset, the homogeneous nature of sampling helps overcoming this limitation and is allowing a reliable representation of the distribution of maternal lineages.

The complexity of the migratory patterns observed here is further emphasized by a discontinuity detected between clusters 7 and 2, which overlaps with a broad area of the rainforest region (encompassing Cameroon, Gabon, Congo and Central African Republic) where the sampling coverage is fairly homogeneous. Cultural factors do not seem to offer an explanation for this separation. In fact, the populations composing the two clusters speak languages that are closely related, within the Narrow Bantu family and show no major differences in their subsistence economy. On the other hand, environmental factors could have played a role if one considers that the rainforest habitat may decrease the intensity of gene flow among populations after their initial settlement in deforested areas, making migration more difficult. Another discontinuity in the pattern (between 
clusters 1 and 6) overlapped with a gap in the sampling coverage of the dataset under study, corresponding to the area of Guinea, the Ivory Cost and Liberia, where tropical rainforest vegetation generally prevails. In the absence of these samples, any further inference on the validity of the observed discontinuity would be very speculative. However, their analysis could contribute to a more exhaustive testing of the influence of different environments on the intensity of migrations among human populations.

Considering all the previous observations, we suggest that farming rainforest populations have probably undergone a local, more recent, and less intense demographic expansion than other food producer populations of the Niger-Congo phylum, which has been previously observed in Gabon through the analysis of Y chromosome lineages [29]. Evidence of ancient peopling should also be taken into account when interpreting genetic data. In fact, central Africa is characterized by a well-defined succession of Middle Stone Age industries while western Africa seems to have been populated at very low densities until 10-12 kya $[47,55]$. Rainforest farmers have also been shown to share both recent and ancient genetic backgrounds with hunter-gatherer populations [56-60].

It is interesting to note the unexpected association observed in cluster 6 where populations of nomadic shepherds from Northern Cameroon (Tali, Tupuri and FulbeC; see also MDS plot in Figure 1) were grouped together with Western groups. Complex relationships among Cameroon ethnic groups have already been reported in previous studies $[21,24,29,61]$. Although the intermediate model we tested was not the best supported by the analysis, it actually detected high migration rates from cluster 6 to clusters 3 and 4 (data not shown). Mixed hierarchical models of migration combined with a better knowledge of the nomadic routes followed by these populations would be worth investigating in order to clarify our findings.

Focusing on the genetic variation of Niger-Congospeaking populations, our results highlighted a stronger structure among the populations settled in the Central area, which correspond to the Bantu-speaking groups. In fact, populations settled in Nigeria and Ghana (clusters 3 and 1) and Guinea Bissau and Senegal (clusters 6 and 5), which present a high linguistic diversity, seem to be characterized by a rather continuous gene flow and show smaller inter-population differences. This contradicts the expectations described above, based on linguistic data, of a recent demic expansion from the area of Nigeria-Cameroon towards Central Southern and Eastern Africa, and an earlier diffusion from Western to Central Africa [26].

As a general conclusion, language does not seem to be the main predictor for the distribution of genetic variation among Niger-Congo-speaking populations. Despite the general belief that language is transmitted by migrating women, genetic analyses have repeatedly shown its preferential correlation with paternal rather than maternal genetic variation $[12,13,21]$.

Unfortunately, we were unable to find a reliable approach for the definition of linguistic distances. Comprehensive classifications based on a quantitative measure of lexical similarities are only available for the Narrow Bantu languages, and not systematically for other Niger-Congo branches (Koen Bostoen, personal communication). Since in this dataset only $28 / 85$ populations belong to the Narrow Bantu family, we decided to avoid this approach in order not to introduce interpretation biases due to inaccurate or questionable linguistic classification.

Even though the genetic clusters here reported cannot be considered as random mating units, the picture presented in our study suggests that, in particular thanks to female-biased movements, gene flow occurs among human populations speaking very different languages.

The analysis of paternal patterns of migration would be useful to shed light on the substructure and the random mating areas among patrilocal populations, while autosomal and X-chromosomal data could be productively investigated to explore whether sex-biased movements are detectable in the distribution of genome variation.

\section{Conclusions}

In this paper, we present a genetic study on female patterns of migration in populations from Central and Western Africa which share a patrilocal tradition and belong to the same linguistic phylum. Our results show how macro habitats seem to play a major role in determining population genetic structure. Population samples from Guinea, the Ivory Coast and Liberia could allow us to test whether this working hypothesis applies to an even larger area of the continent. However, we highlight here how fundamental the knowledge of cultural factors is when planning a population genetic study. In fact, having reliable information about matrimonial behaviour, even the resolution provided by a relatively small region of mtDNA, proved useful in inferring complex patterns of migration and isolation.

\section{Methods \\ Sampling and database}

Our dataset contains 4175 individuals from 85 NigerCongo speaking populations from Western-Central subSaharan Africa (15 Cameroon, 1 Central African Republic, 1 Congo, 17 Gabon, 5 Ghana, 7 Guinea Bissau, 27 Nigeria, 4 Sierra Leone, 3 Senegal; see Additional file 1: Table S1 for further details and Additional file 3: Figure S1a for exact geographical locations). Eighty were obtained from a systematic mining of mtDNA online databases [62] and from current literature, while the remaining 5 were analysed for this study. A total of 230 
samples were collected from 3 Nigerian populations (37 Idoma, 41 Igala and 51 Tiv) and 2 Congolese populations (53 North Bateke and 48 Beti). The map of biomass reconstructed by Baccini et al., (2008) [43] was used to assign each population to the savannah or the rainforest group (see Table 2). The threshold for an area to be defined forest is 112 or more of biomass index [43]. Linguistic affiliation, which was defined according to Ethnologue's classification, is reported in Additional file 1: Table S1 ([63] Ethnologue: SIL International. Online version: http://www.ethnologue.com/), while a tree representing structure within Niger-Congo and relations among languages spoken in the populations analysed is presented in Additional file 3: Figure S1b. Sample collection methodology and the aims of the study have been approved by the ethical committees of the University of Ibadan and Sapienza University of Rome. The sampling took place in hospitals under the supervision of the local medical staff in compliance with the Helsinki Declaration. Each participant signed an informed consent which was drafted in English. The forms included the following information: 1) aims, procedure and scientific benefits, absence of economical benefits; 2) the fact that potential injuries related to withdrawal of the check swabs would be treated by the medical staff; 3) personal information about the volunteer is not transferred in digital format and stored as physical brochure; 4) participants can withdraw at any moment; 5) no material is stored in biobanks.

The HVR1 of mtDNA, from position 16024 to 16383 , was sequenced in all individuals and used for all further analyses. Sequencing was carried out according to Vigilant et al. (1989) [64], with minor modifications. HVR1 was amplified using primers L15996 and H16401, and then sequenced on both strands using the BigDye Terminator v3.1 Cycle Sequencing Kit (Applied Biosystems). The quality control of the final data was performed through a phylogenetic approach and each missing diagnostic mutation or private change was confirmed through resequencing. Haplogroup assignment was carried out manually and labelling was performed in agreement with PhyloTree [65]. The haplotypes and haplogroups for the newly typed populations are provided in Additional file 9: Table S4. Haplogroup frequencies for the 85 populations included in the study are reported in Additional file 10: Table S5.

\section{Statistical analyses}

Intra-population diversity parameters, Fu's neutrality test, pairwise genetic distances, AMOVA and Mantel test statistics were calculated using Arlequin 3.5 software [66]. The distance matrix was represented in a nonmetric multidimensional scaling (MDS) plot using the SPSS 15.0 software (SPSS for Windows, Rel. 11.2006.
Chicago: SPSS Inc). A Wilcoxon Mann-Whitney test was used to compare two sets of Fu's statistical values and was performed with an $\mathrm{R}$ base package ( $\mathrm{r}$-base-core; R Core Development Team 2011; [67]).

Genetic structure was inferred through the Discriminant Analysis of Principal Components (DAPC; [38]). To analyse population structure with mtDNA, we used the matrix of mtDNA mutation frequencies calculated at population level. In this way, all the variation in the individual sequences is included, and the principal components (PC) naturally retrieve the correlation among the variables. Applying the PC analysis directly to individual mtDNA sequences would otherwise have detected the pattern of phylogenetic relationships among the haplogroups [68].

The first step of the structure analysis consisted in assigning populations or individuals to clusters through the $k$-means approach, which relies on classical ANOVA. This method maximizes the variance among groups and minimizes the variance within groups. The Bayesian Information Criterion (BIC) was used to detect the best number of groups comparing the decrease of the residual variance among different numbers of clusters, with the best number corresponding to the minimum $\mathrm{BIC}$ value [38].

DAPC was performed on the clusters inferred with the $k$-means in order to investigate their separation which is summarized by the discriminant components [38]. This analysis is composed by a first step, a classical PC analysis, and a second step, which is the actual discriminant analysis applied to the matrix of principal components. The components, or discriminant functions, thus maximize the ratio of the variance among groups and the variance within groups. Group positions, defined by the discriminant functions, are presented in a scatterplot. The residual of the probability of population assignment to true clusters versus randomly permuted clusters (a.score) was calculated to test the goodness-offit of the discriminant analysis [67,69,70].

A simple linear regression analysis was performed to evaluate the correlation between genetic and geographic distances among the clusters using the geographic coordinates of their centroids (calculated as mean(lat) and mean (long) of the populations in the cluster). This was then plotted for both East to West and West to East directions [67].

Mega 5.05 software was used to calculate the alpha value of the gamma distribution for the mutation rate of the whole dataset and to obtain trees of Minimum Evolution for the sequences included in each cluster (see Supplementary Materials for further details; [71]).

Once the unbiased structure of the populations under study was determined, the migration pattern among the clusters identified was tested through a Bayesian approach, which is implemented in migrate- $\mathrm{n}$ software version 3.2.9 $[39,41]$. The software also allows maximum likelihood 
inference to be drawn, but Bayesian estimation was seen to be more efficient when using data from a single locus [40]. Three migration schemes were modelled and compared, with the aim of explaining the distribution of the clusters in the DAPC plot integrated with their geographical relative locations. The first (model A) is a full island model where all the clusters are allowed to interchange migrants and can be considered as a null model without prior assumptions. The second (model B) is a linear steppingstone model where cluster 2 and 5 are at the extremes. This is the most parsimonious model allowable, where the connections among the clusters are assigned taking into account both their positions on the discriminant axes and the geographical region most represented in each cluster. The last one (model C) is intermediate between a stepping-stone (Central clusters: 2, 7 and 4) and a full island model (Central-Western and Western clusters: 4, 3, 1, 6 and 5), where cluster 4 represents the link between the two schemes. In model $\mathrm{C}$, we excluded the connection between clusters 4 and 5 , since they do not share any population from a common region and they are also separated by the third discriminant component (data not shown). The rationale for the intermediate model is based exclusively on the pattern highlighted in the the DAPC plot. Here, cluster 2 is very well separated from cluster 4, suggesting no close migratory relation and an overall stepping stone model for cluster 4, 7 and 2. The best model was chosen through the Log Bayes Factor (LBF) calculation, which was carried out using the value of thermodynamic integration instead of the harmonic mean, since the latter has been shown to be less reliable $[40,72]$. The parameters estimated are theta $(\Theta)$ and migration rates $(M)$ expressed as the number of migrants. Model details and specific run conditions are provided in a supplementary text.

In order to reduce the prohibitive computational time, migration estimates were carried out on a proportional sub-sampling of each cluster. A random sub-set accounting for 30\% of each cluster, for a total of 1024 individuals, was pooled five times. Considering the high amount of samples included in cluster 3 and the fact that they belong to a very small geographical area, which is overrepresented in comparison to the rest of the region, the cluster 3 sampling was reduced to $15 \%$ in order to obtain a comparable sample size for all clusters. Each model was then run 3 times for each different sub-dataset for a total of 45 runs. Log Bayes Factors were calculated as follows for a total of 45 crossed comparisons among pairs of models:

$$
\begin{aligned}
\text { Log BayesFactor } & =21 n(\operatorname{Prob}(D \mid \text { Model1 }) \\
& -(\operatorname{Prob}(D \mid \text { Model } 2))
\end{aligned}
$$

Sub-samples were compared with the original sample through basic summary statistics using Arlequin 3.5 software [65]. Comparisons among original clusters and relative sub-samplings for gene diversity and mean number of pairwise differences were found to be non-significant, as well as the $\mathrm{F}_{\mathrm{ST}}$ values among each cluster and its subsets (Additional file 5: Table S3 and data not shown). The number of polymorphic sites showed a decrease in $10-20 \%$ of the original value, which is to be expected given that this statistic is directly dependent on the sample size. Although this does not influence the estimates of theta $(\Theta)$ values, the loss of rare haplotypes in the sub-samples may lead to underestimated migration rates. For this reason, instead of calculating the number of immigrants $(2 \mathrm{Nm})$, we discuss the $M$ value which represents the immigration rates scaled for the mutation rate per site per generation $(\mathrm{m} / \mu)$ and which indicates the relative contribution of migration over mutation processes to the variation observed.

\section{Additional files}

\begin{abstract}
Additional file 1: Table S1. Database used in the present study. The populations are listed in a geographical order from East to West with their linguistic affiliation according to ethnologue.com.
\end{abstract}

Additional file 2: Table S2. Pairwise genetic distances matrix among populations. Non-significant distances are reported as null.

Additional file 3: Figure S1. a) Map of geographical positions of the 85 populations analysed in the present study: central (green), centralwest (red), west (blue). b) Phylogenetic relationships among the languages spoken by the 85 populations analysed in the present study graphically reproduced according to ethnologue.com.

Additional file 4: Figure S2. a) Curve of BIC decreasing in relation to number of clusters considered. The minimum BIC value corresponds to number of clusters $=7$. b) Assignation of the populations to the clusters. The intensity of the colour is proportional to probability of assignation.

Additional file 5: Table S3. Summary statistics for the 45 sub-datasets compared with the original sample belonging to each of the 7 clusters individuated. $\mathrm{N}$ is the number of individuals, $\mathrm{K}$ the number of haplotypes, $\mathrm{k} / \mathrm{N}$ is ratio between the two previous values, $\mathrm{S}$ is the number of segregating sites and \%S the percentual retain of variability in comparison with the original sample. HD is the haplotype diversity, MNPD the mean number of pairwise differences.

Additional file 6: Figure S3. Minimum Evolution tree topologies for the 7 DAPC clusters (see Supplementary Material for further details). The tree for cluster 3 was divided across 9 pages for a better graphical visualization

Additional file 7: Figure S4. Plot of the linear regression between genetic vs geographic distances based on the clusters' centroids. a) The linear distances are calculated starting from cluster 5 in direction West to East. b) The linear distances are calculated starting from cluster 2 in direction East to West.

Additional file 8: Figure S5. Posterior distributions of the parameters estimated with migrate-n $(\theta$ and $M)$ for one of the 15 runs.

Additional file 9: Table S4. Haplotypes found in the populations typed in the present study.

Additional file 10: Table S5. Frequencies of the main haplogroups in the populations analysed.

\section{Competing interests}

The authors declare no competing interests. 


\section{Authors' contributions}

VaM, CB, GDB, MP designed the research. VeM, CB, DC conceived and designed the experiments. VaM, VeM, OA provided the samples. DC contributed with reagents and materials. VeM performed the experiments and built the database. VaM analysed the data. VaM and CB wrote the paper with the contribution of GDB. All authors read and approved the final manuscript.

\section{Acknowledgements}

This study was made possible thanks to the contribution of all the DNA donors from sub-Saharan Africa. The laboratory of Molecular Anthropology of Sapienza University of Rome (Italy) and the University of Ibadan (Nigeria) collaborated for the sampling in the Benue River Valley. We are grateful to Thibaut Jombart (Imperial College London, UK) and Peter Beerli (Florida States University, USA) for developing the elegant methods which made this work possible and for their patient willingness in answering our queries. We would also like to thank Mark Jobling (University of Leicester, UK) and Richard Nichols (Queen Mary University of London, UK) for their useful comments and revisions; and Roger Anglada, Stephanie Plaza and Mònica Vallés (Universitat Pompeu Fabra, Barcelona, Spain) for their technical support. Finally, we would like to thank anonymous reviewers which helped invaluably to the final quality of the manuscript. This research was partially supported by the Istituto Italiano di Antropologia and the University of Rome "La Sapienza" (funds to GDB).

\section{Data archiving}

Data are available either from the AnthroDigit ${ }^{\text {data }}$ repository (http://www. isita-org.com/Anthro-Digit/data.htm) or through Genbank (accession numbers KC544024 - KC544253).

\section{Author details}

${ }^{1}$ Dipartimento di Biologia Ambientale, Sapienza Università di Roma, P.le Aldo Moro 5, 00185, Rome, Italy. ²Dipartimento di Storia, Culture, Religioni, Sapienza Università di Roma, P.le Aldo Moro 5, 00185, Rome, Italy. ${ }^{3}$ Istituto Italiano di Antropologia, P.le Aldo Moro 5, 00185, Rome, Italy. ${ }^{4}$ Department of Zoology, University of Ibadan, Ibadan, Oyo State, Nigeria. ${ }^{5}$ Institut de Biologia Evolutiva (CSIC-UPF), Departament de Ciències Experimentals i de la Salut, Universitat Pompeu Fabra, Doctor Aiguader 88, 08003, Barcelona, Spain. ${ }^{6}$ Department of Genetics, University of Leicester, Leicester LE1 7RH, UK. ${ }^{7}$ Current address: Department for Integrative Biology and Evolution, University of Veterinary Medicine, Savoyenstr. 1a, A-1160, Wien, Austria.

Received: 3 August 2012 Accepted: 25 January 2013

Published: 29 January 2013

\section{References}

1. Salas A, Richards M, De la Fe T, Lareu MV, Sobrino B, Sanchez-Diz P, Macaulay V, Carracedo A: The making of the African mtDNA landscape. Am J Hum Genet 2002, 71(5):1082-1111.

2. Rosenberg NA, Pritchard JK, Weber JL, Cann HM, Kidd KK, Zhivotovsky LA, Feldman MW: Genetic structure of human populations. Science 2002, 298(5602):2381-2385.

3. Prugnolle F, Manica A, Balloux F: Geography predicts neutral genetic diversity of human populations. Curr Biol 2005, 15(5):R159-R160.

4. Li JZ, Absher DM, Tang H, Southwick AM, Casto AM, Ramachandran S, Cann HM, Barsh GS, Feldman M, Cavalli-Sforza LL, Myers RM: Worldwide human relationships inferred from genome-wide patterns of variation. Science 2008, 319(5866):1100-1104.

5. Novembre J, Johnson T, Bryc K, Kutalik Z, Boyko AR, Auton A, Indap A, King KS, Bergmann S, Nelson MR, Stephens M, Bustamante CD: Genes mirror geography within Europe. Nature 2008, 456(7218):98-101.

6. Thangaraj K, Naidu BP, Crivellaro F, Tamang R, Upadhyay S, Sharma VK, Reddy AG, Walimbe SR, Chaubey G, Kivisild T, Singh L: The influence of natural barriers in shaping the genetic structure of Maharashtra populations. PLoS One 2010, 5(12):e15283.

7. Chaubey G, Metspalu M, Choi Y, Magi R, Romero IG, Soares P, van Oven M, Behar DM, Rootsi S, Hudjashov G, Mallick CB, Karmin M, Nelis M, Parik J, Reddy AG, Metspalu E, van Driem G, Xue Y, Tyler-Smith C, Thangaraj K, Singh L, Remm M, Richards MB, Lahr MM, Kayser M, Villems R, Kivisild T: Population genetic structure in Indian Austroasiatic speakers: the role of landscape barriers and sex-specific admixture. Mol Biol Evol 2011, 28(2):1013-1024.

8. Cavalli-Sforza LL, Menozzi P, Piazza A: The history and geography of human genes. Princeton: Princeton University Press; 1993

9. Jobling MA, Hurles ME, Tyler-Smith C: Human evolutionary genetics. New York and Abingdon: Garland Science; 2004.

10. Scheinfeldt LB, Soi S, Tishkoff SA: Colloquium paper: working toward a synthesis of archaeological, linguistic, and genetic data for inferring African population history. Proc Natl Acad Sci USA 2010, 107(Suppl 2):8931-8938.

11. Quintana-Murci L, Krausz C, Zerjal T, Sayar SH, Hammer MF, Mehdi SQ, Ayub Q, Qamar R, Mohyuddin A, Radhakrishna U, Jobling MA, Tyler-Smith C, McElreavey K: Y-chromosome lineages trace diffusion of people and languages in southwestern Asia. Am J Hum Genet 2001, 68(2):537-542.

12. Lane $A B$, Soodyall $H$, Arndt $S$, Ratshikhopha ME, Jonker E, Freeman C, Young L, Morar B, Toffie L: Genetic substructure in South African Bantu-speakers: evidence from autosomal DNA and Y-chromosome studies. Am J Phys Anthropol 2002, 119(2):175-185.

13. Wood ET, Stover DA, Ehret C, Destro-Bisol G, Spedini G, McLeod H, Louie L, Bamshad M, Strassmann Bl, Soodyall H, Hammer MF: Contrasting patterns of $Y$ chromosome and mtDNA variation in Africa: evidence for sexbiased demographic processes. Eur J Hum Genet 2005, 13(7):867-876.

14. Seielstad MT, Minch E, Cavalli-Sforza LL: Genetic evidence for a higher female migration rate in humans. Nat Genet 1998, 20(3):278-280.

15. Oota H, Settheetham-Ishida W, Tiwawech D, Ishida T, Stoneking M: Human mtDNA and Y-chromosome variation is correlated with matrilocal versus patrilocal residence. Nat Genet 2001, 29(1):20-21.

16. Wilder JA, Kingan SB, Mobasher Z, Pilkington MM, Hammer MF: Global patterns of human mitochondrial DNA and Y-chromosome structure are not influenced by higher migration rates of females versus males. Nat Genet 2004, 36(10):1122-1125.

17. Hamilton $\mathrm{G}$, Stoneking M, Excoffier L: Molecular analysis reveals tighter social regulation of immigration in patrilocal populations than in matrilocal populations. Proc Natl Acad Sci USA 2005, 102(21):7476-7480

18. Wilkins JF, Marlowe FW: Sex-biased migration in humans: what should we expect from genetic data? Bioessays 2006, 28(3):290-300.

19. Ramachandran S, Deshpande O, Roseman CC, Rosenberg NA, Feldman MW, Cavalli-Sforza LL: Support from the relationship of genetic and geographic distance in human populations for a serial founder effect originating in Africa. Proc Natl Acad Sci USA 2005, 102(44):15942-15947.

20. Rosenberg NA, Mahajan S, Gonzalez-Quevedo C, Blum MG, Nino-Rosales L, Ninis V, Das P, Hegde M, Molinari L, Zapata G, Weber JL, Belmont JW, Patel PI: Low levels of genetic divergence across geographically and linguistically diverse populations from India. PLoS Genet 2006, 2(12):e215.

21. Coia V, Brisighelli F, Donati F, Pascali V, Boschi I, Luiselli D, Battaggia C, Batini C, Taglioli L, Cruciani F, Paoli G, Capelli C, Spedini G, Destro-Bisol G: A multiperspective view of genetic variation in Cameroon. Am J Phys Anthropol 2009, 140(3):454-464.

22. Krings M, Salem AE, Bauer K, Geisert H, Malek AK, Chaix L, Simon C, Welsby D, Di Rienzo A, Utermann G, Sajantila A, Paabo S: Stoneking M: mtDNA analysis of Nile River Valley populations: A genetic corridor or a barrier to migration?. Am J Hum Genet 1999, 64(4):1166-1176.

23. Quintana-Murci L, Chaix R, Wells RS, Behar DM, Sayar H, Scozzari R, Rengo C, Al-Zahery N, Semino O, Santachiara-Benerecetti AS, Coppa A, Ayub Q, Mohyuddin A, Tyler-Smith C, Qasim Mehdi S, Torroni A, McElreavey K: Where west meets east: the complex mtDNA landscape of the southwest and Central Asian corridor. Am J Hum Genet 2004, 74(5):827-845.

24. Tishkoff SA, Reed FA, Friedlaender FR, Ehret C, Ranciaro A, Froment A, Hirbo JB, Awomoyi AA, Bodo JM, Doumbo O, Ibrahim M, Juma AT, Kotze MJ, Lema G, Moore JH, Mortensen H, Nyambo TB, Omar SA, Powell K, Pretorius GS, Smith MW, Thera MA, Wambebe C, Weber JL, Williams SM: The genetic structure and history of Africans and African Americans. Science 2009, 324(5930):1035-1044.

25. Henn BM, Gignoux CR, Jobin M, Granka JM, Macpherson JM, Kidd JM, Rodriguez-Botigue L, Ramachandran S, Hon L, Brisbin A, Lin AA, Underhill PA, Comas D, Kidd KK, Norman PJ, Parham P, Bustamante CD, Mountain JL, Feldman MW: Hunter-gatherer genomic diversity suggests a southern African origin for modern humans. Proc Natl Acad Sci USA 2011, 108(13):5154-5162.

26. Ehret $C$ : Language and history. In African languages: an introduction. Edited by Heine B, Nurse D. Cambridge: Cambridge University Press; 2000:272-297. 
27. Sikora M, Laayouni H, Calafell F, Comas D, Bertranpetit J: A genomic analysis identifies a novel component in the genetic structure of subSaharan African populations. Eur J Hum Genet 2011, 19(1):84-88.

28. de Filippo C, Barbieri C, Whitten M, Mpoloka SW, Gunnarsdottir ED, Bostoen K, Nyambe T, Beyer K, Schreiber H, de Knijff P, Luiselli D, Stoneking M, Pakendorf B: Y-chromosomal variation in sub-Saharan Africa: insights into the history of Niger-Congo groups. Mol Biol Evol 2011, 28(3):1255-1269.

29. Montano V, Ferri G, Marcari V, Batini C, Anyaele O, Destro-Bisol G, Comas D: The Bantu expansion revisited: a new analysis of $Y$ chromosome variation in Central Western Africa. Mol Ecol 2011, 20(13):2693-2708.

30. Pakendorf B, Bostoen K, de Filippo C: Molecular perspectives on the Bantu expansion: a synthesis. Lang Dynam Change 2011, 1:50-88.

31. Robertshaw P: African Archaeology, Multidisciplinary Reconstructions of Africa's Recent Past, and Archaeology's Role in Future Collaborative Research. Afr Archaeol Rev 2012, 29(2):95-108.

32. Greenberg JH: Studies in African Linguistic Classification: I The NigerCongo Family. Southwestern. J Anthropol 1949, 5:79-100.

33. Baumann H, Westermann D: Les peuples et les civilisations de l'Afrique. Paris: Payot; 1970.

34. Biasutti R: Le razze e i popoli della terra. Vol 3: Africa, Volume 3. Torino: UTET; 1967

35. Murdock GP: Social Structure. New York: Macmillan; 1949.

36. Murdock GP: Africa. Its Peoples and Their Culture History. New York: McGrawHill; 1959.

37. Rosa A, Brehem A: African human mtDNA phylogeography at-a-glance. J Anthropol Sci 2011, 89:25-58.

38. Jombart T, Devillard S, Balloux F: Discriminant analysis of principal components: a new method for the analysis of genetically structured populations. BMC Genet 2010, 11:94.

39. Beerli P, Felsenstein J: Maximum-likelihood estimation of migration rates and effective population numbers in two populations using a coalescent approach. Genetics 1999, 152(2):763-773.

40. Beerli P: Comparison of Bayesian and maximum-likelihood inference of population genetic parameters. Bioinformatics 2006, 22(3):341-345.

41. Beerli P, Palczewski M: Unified framework to evaluate panmixia and migration direction among multiple sampling locations. Genetics 2010, 185(1):313-326.

42. Sturrock K, Rocha J: A multidimensional scaling stress evaluation table. Field Methods 2000, 12:49-60

43. Baccini A, Laporte N, Goetz SJ, Sun M, Dong H: A first map of tropical Africa's above-ground biomass derived from satellite imagery. Environ Res Lett 2008, 3(4). doi:10.1088/1748-9326/3/4/045011.

44. Plaza S, Salas A, Calafell F, Corte-Real F, Bertranpetit J, Carracedo A, Comas $D$ : Insights into the western Bantu dispersal: mtDNA lineage analysis in Angola. Hum Genet 2004, 115(5):439-447.

45. Beleza S, Gusmao L, Amorim A, Carracedo A, Salas A: The genetic legacy of western Bantu migrations. Hum Genet 2005, 117(4):366-375.

46. Williamson K, Blench R: Niger-Congo. In African Languages - An Introduction. Edited by Heine B, Nurse D. Cambridge: 42; 2000:11.

47. Blench R: Archaeology, language, and the African past. Lanham, MD: Oxford: AltaMira Press; 2006

48. Jansen F, Ufkes E, Bey Khelifa L: The younger Dryas in equatorial and southern Africa and in the southeast Atlantic Ocean. In The younger Dryas. 44th edition. Edited by Troelstra SR, Van Hinte JE, Ganssen GM; 1995:141-147.

49. Talbot MR, Jensen NB, Tiercelin J: An abrupt change in the African monsoon at the end of the Younger Dryas. Geochem Geophys Geosyst 2007, 8(3):1-16.

50. Hamilton AC, Taylor D: History of climate and forests in tropical Africa during the last 8 million years. Clim Chang 1991, 19(1-2):65-78.

51. Manica A, Prugnolle F, Balloux F: Geography is a better determinant of human genetic differentiation than ethnicity. Hum Genet 2005, 118(3-4):366-371.

52. Ramirez-Soriano A, Ramos-Onsins SE, Rozas J, Calafell F, Navarro A: Statistical power analysis of neutrality tests under demographic expansions, contractions and bottlenecks with recombination. Genetics 2008, 179(1):555-567.

53. Ray N, Excoffier L: Inferring past demography using spatially explicit population genetic models. Hum Biol 2009, 81(2-3):141-157.
54. Balloux F, Handley L, Jombart T, Liu H, Manica A: Climate shaped the worldwide distribution of human mitochondrial DNA sequence variation. Proc Biol Sci 2009, 276(1672):3447-3455.

55. Cornelissen E: Human responses to changing environments in Central Africa between 40,000 and 12,000 BP. J World Prehist 2002, 16(3):197-235.

56. Batini C, Coia V, Battaggia C, Rocha J, Pilkington MM, Spedini G, Comas D, Destro-Bisol G, Calafell F: Phylogeography of the human mitochondrial L1c haplogroup: genetic signatures of the prehistory of Central Africa. Mol Phylogenet Evol 2007, 43(2):635-644.

57. Quintana-Murci L, Quach H, Harmant C, Luca F, Massonnet B, Patin E, Sica L, Mouguiama-Daouda P, Comas D, Tzur S, Balanovsky O, Kidd KK, Kidd JR, van der Veen L, Hombert JM, Gessain A, Verdu P, Froment A, Bahuchet S, Heyer E, Dausset J, Salas A, Behar DM: Maternal traces of deep common ancestry and asymmetric gene flow between Pygmy hunter-gatherers and Bantuspeaking farmers. Proc Natl Acad Sci USA 2008, 105(5):1596-1601.

58. Berniell-Lee G, Calafell F, Bosch E, Heyer E, Sica L, Mouguiama-Daouda P, van der Veen L, Hombert JM, Quintana-Murci L, Comas D: Genetic and demographic implications of the Bantu expansion: insights from human paternal lineages. Mol Biol Evol 2009, 26(7):1581-1589.

59. Verdu P, Austerlitz F, Estoup A, Vitalis R, Georges M, Thery S, Froment A, Le Bomin S, Gessain A, Hombert JM, Van der Veen L, Quintana-Murci L, Bahuchet $S$, Heyer E: Origins and genetic diversity of pygmy huntergatherers from Western Central Africa. Curr Biol 2009, 19(4):312-318.

60. Batini C, Lopes J, Behar DM, Calafell F, Jorde LB, van der Veen L, QuintanaMurci L, Spedini G, Destro-Bisol G, Comas D: Insights into the demographic history of African Pygmies from complete mitochondrial genomes. Mol Biol Evol 2011, 28(2):1099-1110.

61. Spinola H, Couto AR, Peixoto MJ, Anagnostou P, Destro-Bisol G, Spedini G, Lopez-Larrea C, Bruges-Armas J: HLA Class-I Diversity in Cameroon: Evidence for a North-south Structure of Genetic Variation and Relationships with African Populations. Ann Hum Genet 2011, 75(6):665-677.

62. Congiu A, Anagnostou P, Milia N, Capocasa M, Montinaro F, Destro Bisol G: Online databases for mtDNA and Y chromosome polymorphisms in human populations. J Anthropol Sci 2012, 90:201-215.

63. Lewis MP (Ed): Ethnologue: Languages of the World, Sixteenth edition. Dallas, Tex: SIL International; 2009. Online version: http://www.ethnologue.com/.

64. Vigilant $L$, Pennington $R$, Harpending $H$, Kocher TD, Wilson AC: Mitochondrial DNA sequences in single hairs from a southern African population. Proc Natl Acad Sci USA 1989, 86(23):9350-9354.

65. van Oven M, Kayser M: Updated comprehensive phylogenetic tree of global human mitochondrial DNA variation. Hum Mutat 2009, 30(2):E386-94.

66. Excoffier L, Lischer HE: Arlequin suite ver 3.5: a new series of programs to perform population genetics analyses under Linux and Windows. Mol Ecol Resour 2010, 10(3):564-567.

67. R Core Development Team: R: A Language and Environment for Statistical Computing. Vienna: R Foundation for Statistical Computing; 2009.

68. Alexe G, Satya RV, Seiler M, Platt D, Bhanot T, Hui S, Tanaka M, Levine AJ, Bhanot G: PCA and clustering reveal alternate mtDNA phylogeny of $\mathrm{N}$ and M clades. J Mol Evol 2008, 67(5):465-487.

69. Jombart $\mathrm{T}$ : adegenet: a $\mathrm{R}$ package for the multivariate analysis of genetic markers. Bioinformatics 2008, 24(11):1403-1405.

70. Jombart T, Ahmed I: adegenet 1.3-1: new tools for the analysis of genome-wide SNP data. Bioinformatics 2011, 27(21):3070-3071.

71. Tamura K, Peterson D, Peterson N, Stecher G, Nei M, Kumar S: MEGA5: Molecular Evolutionary Genetics Analysis Using Maximum Likelihood, Evolutionary Distance, and Maximum Parsimony Methods. Mol Biol Evol 2011, 28(10):2371-2379.

72. Kass RRA: Bayes factors and model uncertainty. J Am Stat Assoc 1995, 90:773-795

doi:10.1186/1471-2148-13-24

Cite this article as: Montano et al:: The influence of habitats on female mobility in Central and Western Africa inferred from human mitochondrial variation. BMC Evolutionary Biology 2013 13:24. 